\title{
AFETO E AUTO-ESTIMA NAS RELAÇÕES INTERATIVAS EM INÍCIO DE ESCOLARIZAÇÃO
}

\author{
AFFECTION AND SELF-ESTEEM IN THE INTERACTIVE \\ RELATIONSHIPS IN EARLY SCHOOL EDUCATION \\ L'AFFECTION ET L'AUTO-ESTIME DANS LES RELATIONS \\ INTERACTIVES DANS LA SCOLARISATION INITIALE
}

AFECTO Y AUTOESTIMA EN LAS RELACIONES INTERACTIVAS EN LA EDUCACIÓN INFANTIL

Simão Francisco de Miranda*

\section{RESUMO}

Este artigo, à luz da perspectiva sócio-histórico-cultural, discute o afeto e a auto-estima nas relaçôes diádicas professora-alunos e alunos-alunos no início da escolarização. Discorre acerca dos principais conceitos envolvidos e destaca os papéis da comunicação e da metacomunicação em tais interaçôes, relacionando-os à construção da auto-estima. Sumariza estudo empírico realizado pelo autor envolvendo 12 crianças de uma $1^{a}$ Série do Ensino Fundamental (atual Segundo Ano) de uma escola pública no DF (seis com indícios de desejável e seis de indesejável auto-estima). Objetivou, entre outras questôes, compreender as possiveis motivaçōes potencialmente incrementadoras de mudanças no curso dos processos de construção da auto-estima, a partir das interaçôes comunicativas e metacomunicativas diádicas criançascrianças e professora-crianças. Entre as principais conclusöes, sugere-se o premente e permanente investimento na qualidade das interaçôes comunicacionais e metacomunicacionais afetivas no contexto estudado para a ampliação das possibilidades da construção mais desejável possivel da auto-estima dos nossos pequenos escolares.

Palavras-chave: Afeto. Auto-estima. Desenvolvimento infantil. Início de escolarização.

* Doutor em Psicologia pela Universidade de Brasília (UnB, 2008). Mestre em Educação pela UnB. Docente de Graduação nas Faculdades JK - Taguatinga - DF (simaodemiranda@unb.br. Site: www.simaodemiranda.com.br). 


\section{DOS CONCEITOS POSSÍVEIS EM UM CURTO ESPAÇO}

\section{$\mathrm{O}$ afeto}

O afeto, do latim affectus, corresponde no português (FERREIRA, 1999, p. 62) a "sentimento de amizade", "afeiçoado a", "carinho", "afabilidade". Assim, quando se pensa em "afeição", vêm naturalmente à mente imagens relacionadas a cuidado, acolhimento, aceitação, afago. Em Cunha (1986, p. 19), ao adjetivo afeto somam-se, aos significados anteriores, "sujeito a", "dependente de". Ou seja, receber ou doar afeto representa uma situação de abertura, de sujeição ao ato afetivo. Compreender esse fenômeno requer reconhecer que, entre as necessidades que precisamos suprir para a garantia da sobrevivência, da vivência e da convivência humana no contexto sócio-histórico-cultural, está a do afeto.

Por outro lado, para ser afeto, precisa afetar, tocar, contactar aquele que estava "sujeito a", produzindo uma mudança de estado. Assim, o afeto é uma emoção que logo avistamos, porque se materializa e, desta forma, se comunica, se avista. Então, a emoção passa a ser afeto quando denunciada pelo aspecto comportamental.

Já em Aristóteles (2001) tem-se que a motivação humana é conduzida por meio de dois extremos: afeição e desafeição. Entretanto, não é nada simples o exercício de dissecar o afeto enquanto constituinte da psique humana, uma vez que, na sua irretorquível aliança com o plano cognitivo, originariamente visto como uma emoção, pode - noutro momento - fundar-se como um sentimento. As dificuldades começam a se apresentar quando se tenta entender as emoções. $\mathrm{O}$ plano da emoção acolhe os mais diferentes e importantes fenômenos, como a alegria, o medo, a tristeza, a ira e o afeto. Conseqüentemente, o afeto é uma das cinco emoções fundamentais, e o comportamento humano perpassa (e é perpassado) por todas elas, inevitavelmente, ao longo do ciclo vital (life span).

Berne (1995) entende que as emoções são fenômenos que se expressam por meio de reações pujantes, mas de curta duração, a exemplo do medo, do pranto, da paixão ou do riso. Os sentimentos, por seu turno, se diferem por durarem mais tempo e por não se expressarem com pujança, a exemplo da amizade e da ternura. Portanto, a emoção do afeto, se consolidada, pode vir a tomar forma de sentimento do afeto. Dessa forma, se justificam as declaraçôes ao mundo: - Estou me sentindo "assim" ou "assado"! Ainda, se se compreendem as emoçóes como herança evolutiva, uma vez que se utilizava dela como mecanismo de defesa e de garantia à vida nos primórdios, quando - por exemplo - das reaçôes de medo ou de coragem frente ao ambiente ainda inóspito a desbravar, pode-se entender também que o fenômeno da auto-estima já compunha essa estrutura primordial. Investir-se de coragem ou de medo era atitude resultante dos processos de autoatribuição dos valores correspondentes. 


\section{A estima e a auto-estima}

Estima, derivação do verbo latino aestimare (FERREIRA, 1999, p. 836), entre suas acepções, apresenta "apreciar", "prezar"; mas, também, "determinar por cálculo ou avaliação o preço ou valor de". Em Cunha (1986, p. 331), estima compreende "avaliação", "apreço", "amor". "Apreço", "apreciação", como se vê, remetem-se imediatamente a preço, estipular valor, valorar, ao mesmo tempo em que se coaduna com as filigranas do prezar e do amor, às sutilezas da benquerença, ou aos seus opostos mais extremados, que no caso da auto-estima são dirigidas ao próprio sujeito.

James (1890) sugere uma emblemática equação para conceituar auto-estima: o resultado do sucesso dividido pelas aspirações do indivíduo. Parece-nos que a partir daí, assemelham-se todos os demais conceitos que a literatura nos apresenta. Annie Reich (apud BERNET; RICK; BRENDA, 1993), por exemplo, defende que auto-estima pode ser entendida como a expressão da discrepância ou harmonia entre como o sujeito se auto-representa e o desejado conceito de si mesmo. Coopersmith (1967) acena para a auto-estima enquanto um conjunto de valores pessoais que se embute nas atitudes voltadas a si mesmo, representados nas polaridades de auto-aceitação ou de auto-rejeição, de reconhecimento de capacidades ou de incapacidades, de sucesso ou de fracasso, como insinuado no final do parágrafo anterior. Este autor é um dos diversos que se afilia a idéia do afeto como mobilizador fundamental do processo de construção da auto-estima.

\section{DO AFETO, AUTO-ESTIMA E INTERAÇÃO NA SALA DE AULA}

$\mathrm{O}$ afeto exerce papel fundamental na atividade humana e isso faz uma grande diferença no mundo acadêmico, desde os apaixonantes banquinhos da escolinha às temidas bancas das pós-graduaçōes. Sem afeto não haveria interesse, necessidade ou motivação. Conseqüentemente, perguntas nunca seriam feitas e problemas nunca seriam investigados. A afetividade é uma condição necessária na constituição da inteligência, desde a mais tenra idade. Piaget (1962) ressalta que, na relação entre inteligência e afeto, este produz ou pode produzir o desenvolvimento de importantes estruturas cognitivas, tão necessárias na construção dos saberes. Alerta, ainda, que a condição do afeto pode retardar ou acelerar a formação de tais estruturas. Assim, é inquestionável a valorização do afeto na criança em início de escolarização, uma vez que vai coadjuvar na fundação dos pilares da sua auto-estima, considerando-se a qualidade das interações, enquanto "dimensão mais diretamente observável e acessível da relação: as trocas comportamentais entre os agentes sociais" (DEL PRETTE; PAIVA; DEL PRETTE, 2002, p. 64).

Vigotksi (1996) cunha a clássica expressão "função mental" para acenar aos conceitos de pensamento, memória, percepção e atenção, dimensôes pilares do processo educativo. Assim, para ele, a gênese do pensamento está na motivação, no interesse, na necessidade, no afeto e na emoção, que acreditamos serem incrementadores essenciais da auto-estima. 
Conforme Werebe e Nadel-Brulfert (1986), quando Wallon plantou a idéia de uma psicogênese da pessoa completa, levou em conta o sujeito como um todo: afetos, emoções, motricidade e ambiente físico estabelecidos em um mesmo nível. Galvão (1995), ao se referir aos estágios wallonianos do desenvolvimento humano, lembra que esses ocorrem sucessivamente, preponderando o binômio afeto/cognição. Assim, no estágio impulsivo-emocional, característico do primeiro ano de vida, o afeto norteia as reações que a criança apresenta aos que a rodeiam. Portanto, entendemos que, fundada na dimensão cognitiva da auto-estima, a criança já nesse estágio dimensiona as informaçôes percebidas, as idealiza e conclui acerca de si mesma. Na dimensão afetiva, por sua vez, procede às valorações do que julga bom ou ruim em si mesma, em um movimento de gosto ou desgosto, apontando para a construção de sua auto-estima.

Temos em Vigotski (1996, p. 57), rompendo a dicotomia emoção/razão, a idéia primordial da unidade afeto/cognição no desenvolvimento humano. Para ele,

a forma de pensar, que junto com o sistema de conceito nos foi imposta pelo meio que nos rodeia, exclui também nossos sentimentos. Não sentimos simplesmente: o sentimento é percebido por nós sob a forma de ciúme, cólera, ultraje, ofensa. Se dizemos que desprezamos alguém, o fato de nomear os sentimentos faz com que esses variem, já que mantém uma certa relação com nossos pensamentos.

Apoiando-nos, portanto, nos ombros de Vigotski (1996), ao sinalizar que sentimento e pensamento em algum momento se casam, defendemos que a auto-estima surge daquilo que o sujeito representa valorativamente para si mesmo, quando se avalia, cognitiva e/ou afetivamente, nas mais diversas facetas, como a pessoal, a familiar, a social ou a acadêmica.

Garcia (1999, p. 33) soma-se a esse diálogo para postular que "o afeto não pode ficar de fora quando se pretende melhor compreender quem somos, como aprendemos e como nos relacionamos neste nosso mundo". Visto assim, a afetividade - com seus pressupostos interativos - é um elemento fundamental nos processos do desenvolvimento cognitivo humano, notadamente na criança no contexto das primeiras aprendizagens do ensino formal, e deve ser entendida como uma construção sócio-histórico-cultural que ajuda a guiar outra construção: a da sua auto-estima. Os sujeitos de afetos ou desafetos podem resultar desses processos construtivos. A propósito, Schore (2001), neurocientista interessado pela infância, em entrevista à revista The Psychotherapist, afirma que o sujeito constitui-se, em grande parte, de seqüelas das interaçôes mais remotas que teve com os pais e com seus outros significantes. E, parafraseando Garcia (1999), em tais interações a qualidade do afeto não pode ficar de fora. 


\section{DA COMUNICAÇÃO E METACOMUNICAÇÃO DO AFETO NA CONSTRUÇÃO DA AUTO-ESTIMA EM CONTEXTOS DE APRENDIZAGEM}

O indivíduo pode comunicar o afeto de diversas formas: tácteis, verbais, vocais, faciais, gestuais, entre outras. É aqui que entra um essencial componente da comunicação, elemento pouco percebido, mas de intenso poder influenciador (às vezes determinador) no processo de construção da auto-estima: a metacomunicação. É um fenômeno que passa a ter lugar na vida social humana desde que começamos a empreender nossas primeiras relações comunicativas, e assim interativas, com o ambiente. Bateson (1972) a conceitua como um nível da comunicação onde o discurso assume-se como um novo olhar acerca do relacionamento dialógico entre os interlocutores. Ou seja, uma espécie de reavaliação dos conteúdos e das formas como se comunica.

Entendemos a metacomunicação como comunicação verbal ou não-verbal, contínua ou segmentada, explícita ou implícita, compartilhada e orientadora da comunicação propriamente dita, em direção às metas pretendidas pelos interlocutores, e serve, como sugere Wang (1999) ao estudar a metacomunicação no processo de ensino-aprendizagem, para aumentar a consciência acerca da sua própria comunicação e a do outro, transformando não apenas a comunicação, mas a interação com os outros. Ora, se consideramos que a metacomunicação altera a qualidade e a característica das interações, não alteraria igualmente a auto-estima?

A propósito, Maciel, Branco e Valsiner (2004) indicam que:

quando indivíduos interagem entre si, a metacomunicação está sempre ativa como uma espécie de fundo interativo para o conteúdo da comunicação, um fluxo não-verbal contínuo que episodicamente também assume um formato verbal que pode gerar quadros qualitativos contraditórios ou muito complexos para a interpretação das mensagens" (p. 113).

Assim, nos parece que aquilo que não se diz explicitamente no curso do ato comunicativo precisa ser levado em conta quando se quer perceber a ocorrência de processos construtivos, como o da auto-estima. Filigranas como o volume, a cadência e o tom de voz, a gesticulação das mãos, a postura corporal e o olhar podem otimizar ou não o ato comunicativo, podendo conduzi-lo a atuar perniciosamente na construção da auto-estima alheia.

Assim, entendemos que o ato educativo é essencialmente comunicacional e metacomunicacional, dispondo, para que se consolide, dos mesmos canais que usamos (ou não) para comunicarmos o afeto. Portanto, como não defender que as dimensões afetivas e educativas nutrem-se simbioticamente, considerando que o ato educativo pressupõe a necessária existência de relacionamentos interpessoais? Goodlad (1983) defendeu um modelo de aprendizagem participativa, em oposição às tão atuais formas passivas de aprendizagem, que menosprezam o afeto e contribuem para a derrocada da auto-estima dos aprendizes. Estudou mil escolas estadunidenses e concluiu que, em situação de ensino- 
aprendizagem, $70 \%$ do tempo destinado a esse processo era despendido com o professor falando mecanicamente, com todo um conteúdo metacomuncacional, em direção ao aluno, e a segunda maior fatia desse tempo era destinada às atividades escritas dos aprendizes.

Essa é apenas uma das tantas pesquisas que desnudam tal realidade. Um fato não se discute: a comunicação e metacomunicação do afeto e a forma como transita pelas vias das relações interativas o validam como elemento inarredável nos processos de construção da auto-estima, fundamentalmente nas primeiras veredas da jornada escolar.

Sabemos o quanto a privação do afeto compromete o desenvolvimento humano, desde as primeiras experiências de apego materno. Como Valsiner (2001) já apregoara, a vida afetiva humana é a base para todas as condutas, e o desenvolvimento das relações afetivas com o mundo é provavelmente a questão mais básica da psicologia do desenvolvimento. Valsiner (2001) defende que a relação afetiva com o mundo é o alicerce de todo o conjunto dos processos mentais e que os encontros com o ambiente são sempre novos e cheios da incerteza do momento imediatamente posterior. Coadunando-se com essas asserçôes, Coopersmith (1967), Maccoby (1980) e Swayze (1980) assinalam de forma semelhante que as crianças, ao auferirem informaçóes que os adultos significativos têm acerca dela, transformam tais impressões em imagens positivas ou negativas sobre si mesmas. E tais informaçôes podem chegar à criança comunicacional ou metacomunicacionalmente. Dessa forma, o contexto, notadamente o imediato, no lar ou na escola, sustenta a construção da sua auto-estima.

Valsiner (1989) salienta que o desenvolvimento humano é inerentemente social e que toda a estrutura do processo psicológico - cognitivo e afetivo - desenvolve-se em conjunção com o desenvolvimento da interação social da criança. Compreendemos aqui que o processo educativo é eminentemente fundamentado, no plano geral, pelas teias das interaçôes sociais promovidas pelo mesmo, e no plano específico pelos contatos afetivos da criança com seus pares e sua professora, assim como, ao mesmo tempo, consigo mesma. Visto assim, sempre que se considera uma relação interativa, se pressupõe a ocorrência do agrado ou desagrado, que na constância das suas ocorrências vão ajudando na construção da sua auto-imagem.

Calviño (apud LEITE, 1999, p. 103) concebe os afetos como possuidores de "um caráter universal (...) expressivos e, sem exceção, comunicativos no sentido de que implicam em contágio". Novamente surge aqui a questão do contato, do afetar o outro. Prado (1991, p. 67), mineiramente, já alertara no poema Ensinamento: "minha mãe achava estudo a coisa mais fina do mundo. Não é. A coisa mais fina do mundo é o sentimento". Entendemos claramente que o evento prioritário é o sentimento, condição primeira do ensinamento. Ao referir-se a sentimento, Humphreys (2001, p. 16) circunscreve a autoestima a duas expressões dentro de uma frase-chave: "existem duas dimensões principais da auto-estima: o sentimento de ser amado e o sentimento de ser capaz" (grifo nosso). 
Portanto, se o afeto é algo que para existir precisa ser provado, sentido, saboreado, a autoestima o é igualmente.

Minkowski (1999), fenomenólogo da temporalidade, dedicou grande parte do seu trabalho ao pathos humano, a discutir a angústia, o afeto e a expressividade. Vale comentar que, na filosofia, pathos associa-se à noção de paixão e afeto. Largamente utilizado por Sófocles, refere-se - em um dos seus dramas mais conhecidos - à paixão bendita de Antígona, filha de Édipo e Jocasta, dedicada ao seu irmão Hémon. Minkowski (1999) postula que a atenção, a simpatia e o élan pessoal não são atos direcionados ao outro, mas ao mundo. Assim explicita, ao sublinhar o caráter comunicativo-contangiante do afeto:

em um movimento de simpatia, feito em direção de meus semelhantes e ao fazer minhas a sua alegria ou a sua dor, sinto-me comunicar com ele de modo tão íntimo quanto possível; mas, ao mesmo tempo, a este aspecto mais concreto de meu movimento de simpatia, vem se superpor o elemento de plenitude, de contato vital com o vir a ser inteiro (p. 97-100).

O encontro humano se coloca como o sustentáculo primordial do afeto, fundamentalmente na infância, fase na qual o desenvolvimento psicológico intensifica a construção da personalidade, sustentado nas interaçōes do sujeito com seu ambiente. Portanto, as interações promovidas pela professora no contexto de sala de aula podem ou não promover o necessário sentimento de pertencimento e autoconfiança na criança e as conseqüências de uma baixa auto-estima podem ser extremamente danosas.

A percepção mostra-se aqui como um mecanismo de sumo valor. Se a criança percebe o acolhimento, a valorização dos seus esforços, a escuta sensível e verdadeira a partir do professor, ampliará suas possibilidades de acolher, valorizar esforços dos coleguinhas e disponibilizar-se igualmente às escutas sensíveis, colocando em movimento um círculo virtuoso retroalimentador do afeto, favorecendo evidentemente sua auto-estima e, por conseguinte, o processo educativo. Conseqüentemente, como aduz Silva (2004, p. 25), "a afetividade pode ser comparada às lentes de óculos através das quais a criança vê o mundo; no entanto, se as lentes dos óculos estiverem mal ajustadas a criança passa a ter uma visão distorcida da realidade".

\section{DO INVESTIMENTO NO AFETO E NA AUTO-ESTIMA NO CONTEXTO DA APRENDIZAGEM INFANTIL: UM ESTUDO EMPÍRICO}

Utilizando instrumentos de coleta de dados construídos por nós, estudamos, entre 2004 e 2008, a partir da perspectiva qualitativa, 12 crianças de uma primeira série do Ensino Fundamental (atual segundo ano) de uma escola pública no DF. Objetivamos, entre outras questōes, compreender as possíveis motivações potencialmente incrementadoras de mudanças no curso dos processos de construção da auto-estima dos envolvidos, a partir das interações diádicas crianças-crianças e professora-crianças.

Entendendo que as negociaçōes das convergências ou divergências em situação de jogo podiam tornar mais sensíveis à observação os processos interativos relacionados à 
construção da auto-estima, propusemos à professora a realização de 10 jogos cooperativos e/ou competitivos, distribuídos ao longo de oito aulas. Os 12 selecionados se puseram em interação entre eles e com os demais colegas por intermédio das atividades lúdicas, que foram gravadas em vídeo e examinadas quadro-a-quadro na perspectiva microgenética (BRANCO; VALSINER, 1997; FLETCHER; HUFFMAN; BRAY; GRUPE, 1998; SIEGLER; CROWLEY, 1991).

Desde o senso comum, fala-se em "mudança de auto-estima", entende-se que tal mudança seja indicada por variaçóes observáveis no comportamento. De fato, uma pessoa outrora recorrente em baixa autoconfiança e em outro momento visivelmente confiante pode levar os demais a crerem que "mudou sua auto-estima". Entretanto, este estudo compreendeu que oscilações típicas ao fenômeno da auto-estima não podem ser confundidas com mudança. Entendemos que esta só pode ser determinada após uma considerável estabilidade de um novo comportamento, seja ele de incremento ou não, ao longo de certo tempo, o que só poderia ser aproximado por rigorosos instrumentos de mensuração. Por não termos incluído tal estratégia dentre nossas orientaçōes teórico-metodológicas, nos referimos cuidadosamente apenas à identificação de possíveis motivações potencialmente incrementadoras de mudanças no curso dos processos de construção da auto-estima dos sujeitos estudados, considerando suas trocas interativas no contexto das atividades estruturadas das quais participaram.

Entre as principais conclusōes, tivemos que as interações comunicativa e metacomunicativa, afetiva e respeitosa, escolhidas pela professora para advertir ou intervir, atuavam colaborativamente na construção das relaçôes relativas ao processo de construção do self e, assim, da auto-estima das crianças.

Aludimos que o gesto físico atencioso e afetivo da professora repercutia na forma de oscilação positiva no comportamento da criança.

Sugerimos que a qualidade da mediação estabelecida pela professora, distribuindo de modo equilibrado os turnos dialógicos e promovendo continuamente as interaçóes, possibilitava na via comunicacional, além de uma melhor percepção da realidade por parte das crianças, o trânsito de sugestôes de elevação/manutenção da auto-estima delas.

Entendemos que a percepção da professora no sentido de não perder os feedbacks comunicacionais e metacomunicacionais com a turma foi de positivo valor para os processos de construção de auto-estima das crianças; constatamos a metacomunicação como importante mecanismo nas relações interativas estabelecidas no ambiente, na medida em que se caracterizou como um pano de fundo para a operação dos processos de construção da auto-estima.

Acreditamos que os encontros comunicativos e metacomunicativos singelos das crianças entre si e destas com a professora podem ter possibilitado o estímulo de habilidades psicossociais, cognitivas, afetivas, criativas, psicomotoras diversas e podem ter apontado possibilidades orientadas para seus amanhãs, quiçá como futuros adultos altruístas e afetivos. 


\section{CONSIDERAÇÕES FINAIS}

Finalmente, neste incessante devenir humano, defendemos a intensificação de estudos voltados ao bem-estar psíquico da criança, pois para com ela a humanidade tem uma dívida histórica, representada pela insignificância, invisibilidade, brutalização, indignidades, esquecimento e abandono ao longo da nossa história (DEMAUSE, 1995; UNICEF, 2005, 2006 , 2007 e 2008). Urge ampliarmos as possibilidades de compreensão dos fenômenos que guiam a dimensão do afeto e a construção da auto-estima da criança em situação de aprendizagens primeiras, da valorização da afetividade e da auto-estima em todas as açōes humanas, destacadamente nas relações interativas comunicacionais e metacomunicacionais do processo educativo infantil.

Entendemos que os profissionais da educação de crianças em início de escolarização (professores, coordenadores pedagógicos, psicólogos, psicopedagogos e gestores) devem empenhar-se em levar esta discussão às Coordenaçôes Pedagógicas, na promoção de Oficinas e Cursos de Aperfeiçoamento no sentido do alinhavar as práticas pedagógica e psicopedagógica às questôes do afeto e das interaçôes comunicativas e metacomunicativas no contexto da sala de aula e suas relaçóes com a construção da auto-estima dos nossos pequenos.

\section{Referências}

ARISTÓTELES. Ética a Nicômacos. Brasília: Edunb, 2001.

BATESON, Gregory. Steps to an ecology of mind: collected essays in anthropology, psychiatry, evolution, and epistemology. New York: Ballantine, 1972.

BERNE, Eric. Os jogos da vida: a psicologia transacional e o relacionamento entre as pessoas. São Paulo: Nobel, 1995.

BERNET, Christine; RICK, Ingram; BRENDA, Johnson. Selfesteem. In: COSTELLO, Charles G. (Ed.). Symptoms of depression. New York: Wiley, 1993. p. 85-86.

BRANCO, Ângela; VALSINER, Jaan. Changing methodologies: a co-construtivist study of goal orientation in social interactions. Psychology and Developing Societies, London, v. 9, n. 1, p. 35-64, 1997.

COOPERSMITH, Stanley. The antecedents of self-esteem. San Francisco: Freeman, 1967.

CUNHA, Antônio. Dicionário etimológico Nova Fronteira da lingua portuguesa. Rio de Janeiro: Nova Fronteira, 1986.

DEL PRETTE, Zilda; PAIVA, Mirella; DEL PRETTE, Almir. Contribuições do referencial das habilidades sociais para uma abordagem sistêmica na compreensão do processo de ensino-aprendizagem. Interaçôes, São Paulo, v. 10, n. 20, p. 57-72, jul.-dez., 2005.

DeMAUSE, Lloyd. Historia de la infancia. Madrid: Alianza, 1995.

FERREIRA, Aurélio Buarque. Novo Aurélio século XXI: O dicionário da língua portuguesa. Rio de Janeiro: Nova Fronteira, 1999. 
FLETCHER, Kathryn; HUFFMAN, Lisa; BRAY, Norman; GRUPE, Lisa. The Use of the Microgenetic Method with Children with Disabilities: Discovering Competence. Developmental Theory and Research, Philadelphia, v. 9, 1998. Disponível em: <http:/www.uab.edu/cogdev/earlyed.htm>. Acesso em: 6 abr. 2005.

GALVÃO, Isabel. Wallon: uma concepção dialética do pensamento infantil. Petrópolis: Vozes, 1995.

GARCIA, Regina Leite. O afeto entra mais na escola desta vez por outras portas. Revista Proposta, Rio de Janeiro, v. 28, n. 83, p. 32-38, dez. 1999.

GOODLAD, John. A place called school: prospects for the future. Hightstown, New Jersey: McGraw Hill, 1983.

JAMES, William. Principles of psychology. New York: H. Holt, 1890. Disponível em: <http://psychclassics.yorku.ca/James/Principles/prin10.htm>. Acesso em: 30 ago. 2005.

HUMPHREYS, Tony. Auto-estima: a chave da educação para seu filho. São Paulo: Ground, 2001.

LEITE, Isabel. Emoções, sentimentos e afetos: uma reflexão sócio-histórica. Araraquara: JM, 1999.

MACCOBY, Elleanor. Social development. New York: Wiley, 1980.

MACIEL, Diva; BRANCO, Ângela; VALSINER, Jaan. Bidirectional process of knowledge construction in teacher-student transaction. In: BRANCO, Angela; VALSINER, Jaan (Orgs.). Communication and metacommunication human development. Connecticut: IAP, 2004, p. 109-125.

MINKOWSKI, Eugène. Vers une cosmologie. Paris: Éditions Payot \& Rivages. Trad.: Norberto Abreu e Silva Neto para uso dos alunos da disciplina Epistemologia da Psicologia do Instituto de Psicologia da UnB, 1999.

PIAGET, Jean. The relation of affetivity to intelligence in the mental development of the child. Bulletin of the Menninger Clinic, London, v. 26, n. 3, p. 158-200, mar. 1962.

PRADO, Adélia. Poesia reunida. São Paulo: Siciliano, 1991.

SCHORE, Allan. An Interview with Allan Schore, 'the American Bowlby'. In: The Psychotherapist, London, 2001. Disponível em: <www.thinkbody.co.uk/papers/interview-with-allan-s.htm>. Acesso em: 29 nov. 2006.

SIEGLER, Robert; CROWLEY, Kevin. The microgenetic method: a direct means for studying cognitive development. American Psychologist, Washington D.C., v. 46, n. 6, p. 606-620, 1991.

SILVA, Cassiane. Afetividade e cognição: a dicotomia entre o "saber" e o "sentir" na escola. Porto: 2004. Disponível em: <www.psicologia.com.pt/artigos/textos/TL0013.PDF>. Acesso em: 1 dez. 2006.

SWAYZE, Marian. Self-concept development in young children. In: YAWKEY, Thomas D. (Org.). The self-concept of the young child. Provo: Brigham Young University Press, 1980.

UNICEF. Situação mundial da infância. (2005). Disponível em: <www.unicef.org/brazil >. Acesso em: 30 jan. 2008.

. Situação mundial da infância. (2006). Disponível em: <www.unicef.org/brazil>. Acesso em: 30 jan. 2008.

. Situação mundial da infância. (2007). Disponível em: <www.unicef.org/brazil>. Acesso em: 30 jan. 2008. 
UNICEF. Situação mundial da infância. (2008). Disponível em: <www.unicef.org/brazil>. Acesso em: 30 jan.2008.

VALSINER, Jaan. Human development and culture: the social nature of personality and its study. Lexington, MA: Lexington Books, 1989.

. Affective fields and their development. In: . Comparative Study of human cultural development. Madrid: Fundación Infancia y Aprendizaje, 2001, p. 159-181.

VIGOTSKI, Liev Semionovich. Teoria e método em psicologia. São Paulo: Martins Fontes, 1996.

WANG, Younghee. Metacommunication and problem solving in a collaborative task of young children. 1999. 115f. Thesis submitted to the University of Massachusetts for degree of doctor of education. Massachusetts, USA.

WEREBE, Maria José Garcia; NADEL-BRULFERT, Jaqueline. Henri Wallon. São Paulo: Ática, 1986. 


\section{S. F. Miranda}

\section{Affection and self-esteem in the interactive relationships in early school education}

Abstract

This article, in the light of the social-historical-cultural perspective, discusses the affection and self-esteem in the didactic relations between teacher-students and students-students in early school education. Presents the main concepts and outlines the role of communication and metacommunication in such interactions, relating them with the construction of self-esteem. Summarizes the empirical study carried out by the author involving 12 children of one 1st Grade of Primary Education (current Second Year) of a public school of the Federal District (six with and six with no indications of desirable self-esteem). It objectified, among other questions, to understand the possible motivations potentially capable of increasing changes in the course of the processes of construction of self-esteem, starting from the communicative and metacommunicative didactic interactions between children-children and teacherchildren. Among the main conclusions, we suggest the urgent and permanent investment in the quality of affective communication and metacommunication interactions in the context studied to expand the possibilities of the most desirable construction of self-esteem in our small children.

Keywords: Affection. Self-esteem. Child development. Early school education.

\section{L'affection et l'auto-estime dans les relations interactives dans la scolarisation initiale Résumé}

Cet article, à la lumière de la perspective socio-historique-culturelle, discute l'affection et l'auto-estime dans les relations didactiques maître-élève et élèves-élèves en début de scolarisation. Traite de discourir sur les principaux concepts impliqués et met en relief les rôles de la communication et de la metacommunication dans telles interactions, en les mettant en relation avec la construction de l'auto-estime. Fait la synthèse d'une étude empirique réalisée par l'auteur impliquant 12 enfants d'une première année de l'enseignement primaire (actuelle deuxième année) d'une école publique du District Fédéral (six avec et six sans des indices d'auto-estime désirable). Tient comme objet, entre autres questions, de comprendre les possibles motivations qui peuvent potentialiser les changements dans le cours des processus de construction de l'auto-estime, à partir des interactions communicatives et metacommunicatives didactiques enfantsenfants et maître-enfants. Parmi les principales conclusions, nous suggérons l'investissement urgent et permanent dans la qualité des relations didactiques de communication et metacommunication affective dans le contexte étudié pour élargir les possibilités d'une construction plus désirable de l'auto-estime chez nos petits enfants.

Mots clefs : Affection. Auto-estime. Développement de l'enfance. Scolarisation initiale.

\section{Afecto y autoestima en las relaciones interactivas en la educación infantil}

Resumen

Este artículo discute el afecto y la autoestima en las relaciones interactivas promovidas en la educación infantil. Presenta posibilidades conceptuales para ambos constructos y sus relaciones con el binomio inteligencialescolarización, comprendendo que, entre las necesidades para garantizar la supervivencia, la vivencia y la convivencia humana en el contexto sociohistoricocultural, está la afectiva. Discurre acerca de la unidad afecto/cognición a partir de Wallon y Vygotsky; destaca la comunicación afectiva y su papel en la construcción de la autoestima en contextos de aprendizaje. Defende la inversión en el afecto y en la autoestima en el proceso de enseñanza-aprendizaje infantil, tiendo por base un estúdio empirico en curso conducido por el autor de este texto.

Palabras-clave: Afecto. Autoestima. Desarrollo infantil. Educación infantil.

Recebida I ${ }^{\text {a }}$ versão em: | 3.02.2007

Aceita $2^{\mathrm{a}}$ versão em: 28.02.2008 